\title{
Dejen entrar a las mujeres
}

\section{Por Roberto Gargarella}

El 13 de julio de este año, la Cámara Nacional Electoral se pronunció, en "Incidente de Ciudad Futura Nro. 202 - distrito Santa Fe", sobre la validez de una lista presentada por el partido "Ciudad Futura". La lista, como sabemos, se encontraba integrada en su totalidad por precandidatas de sexo femenino. En su decisión, y por mayoría, la Cámara afirmó la decisión del juez federal con competencia electoral cuando solicitó al apoderado de la citada agrupación que presente una nueva nómina de precandidatos compuesta por varones y mujeres.

La decisión de la Cámara resulta errada y desafortunada, por razones diversas. Aquí quisiera detenerme en, y subrayar, los serios problemas del fallo en relación con los modos que entiende la noción constitucional de igualdad; la forma en que se aproxima a las ideologías feministas; su débil teorización sobre la democracia; y, en general, su comprensión del constitucionalismo.

\section{Igualdad}

De los muchos problemas que tiene el fallo, tal vez el más importante y serio sea el relacionado con el modo en que interpreta el valor constitucional de la igualdad. Lo primero que merece decirse al respecto es que la decisión resulta sorprendente cuando se la contrasta con un acercamiento simple y literal a la Constitución, que de modo abierto y explícito se pronuncia i) a favor de la "igualdad real de oportunidades entre varones y mujeres para el acceso a cargos partidarios"; y ii) a favor de la adopción de "acciones positivas en la regulación de los partidos políticos y en el régimen electoral” (art. 37). Frente a la contundencia de tales compromisos, es difícil entender cómo puede hacer un tribunal para bloquear medidas de acción afirmativa, particularmente en el área electoral. La Cámara hace algún modesto esfuerzo por señalar que el artículo 37 "garantiza iguales derechos a ambos sexos, sin ningún tipo de diferenciación", pero es difícil aceptar lo que el tribunal quiere significar con la idea de "ningún tipo de diferenciación", cuando al mismo tiempo toma partido, sin necesidad de hacerlo, por una interpretación constitucional "armónica" (que trate de vincular a las distintas cláusulas entre sí), y no reconoce (lo que entonces debiera reconocer de modo especial, esto es) que de forma también abierta y 
clara, el art. 75 inc. 23, clarifica que las acciones positivas (i) que la Constitución favorece, particularmente en materia electoral (ii), deben orientarse particularmente iii) a favorecer a "las mujeres". Esto es decir, la Constitución "ata" explícitamente la idea de "igualdad real de oportunidades" con acciones positivas, en materia electoral, y en relación con las mujeres. Cómo puede ser, entonces, que luego de este explícito y contundente apoyo de la Constitución, a las acciones positivas en favor de las mujeres, en materia electoral, en nombre de la "igualdad real" de oportunidades, se niegue validez a una lista compuesta sólo por mujeres, y se lo haga en nombre de la "igualdad real” entre los géneros?

La Cámara no argumenta sobre el punto, sino que declara. Declara, por ejemplo, en el considerando 11 de su fallo, que una lista semejante "importaría la vulneración del principio de igualdad”. Y el apoyo que da para tal declaración es un argumento tautológico. La Cámara dice que "una medida de discriminación inversa que afecta al derecho de acceso en condiciones de igualdad...importaría la vulneración del principio de igualdad que implica hacer del sexo una condición de elegibilidad, lo que sería [discriminatorio]”. Esto es, las acciones positivas, si afectan la igualdad, vulneran la igualdad, porque son discriminatorias: una tautología compuesta, basada en una razón equivocada. Ello, dado que las acciones positivas en materia electoral, primariamente, "hacen del sexo una condición de elegibilidad": de eso tratan las acciones positivas a favor de las mujeres.

A pesar de que el análisis de la idea de igualdad debiera ocupar el lugar central en el fallo, la Cámara no atina a elaborar un argumento sólido en la materia, lo cual resulta en extremo preocupante (se encuentra un interesante acercamiento al punto, mientras tanto, en el voto disidente del Juez Corcuera). En el considerando 6, por ejemplo, la Cámara habla del contrasentido que significaría suponer que la Constitución Nacional exige privar a unos de lo que les concede a otros." Pero qué hace, por ejemplo, la ley de "cupo femenino" que la Cámara en este mismo fallo respalda de modo contundente?: priva a unos lo que les concede a otros. Por eso, dicha contundente declaración de la Cámara no agrega ningún argumento, sino que en todo caso nos quita otro, al no poner la atención en el lugar relevante: lo que importa no es si se priva a algunos de lo que se les concede a otros (algo que ocurre permanentemente), sino si se lo hace injustificada o irrazonablemente.

Peor todavía, la Cámara afirma luego, de modo rimbombante, que "nuestro plexo jurídico de base es claro y terminante: igualdad real de oportunidades 
entre varones y mujeres para el acceso a los cargos electivos y partidarios". En efecto, y como vimos, nuestro plexo jurídico es terminante: pide igualdad real de oportunidades, pero en un sentido que contradice lo que la Cámara afirma. Ella aclara que la Constitución "con esa expresión no se refirió solo a la mujer sino a los representantes de los dos géneros, y mal puede, en la consecución del objetivo o finalidad de resguardar la representación igualitaria." Pero ello no es cierto, porque como vimos, la Constitución sólo habla de igualdad real en relación con la adopción de acciones positivas, en materia electoral, y con un sesgo especial y abierto en favor de los derechos electorales de las mujeres (el art. 75 inc. 23 le exige al legislativo: legislar y promover medidas de acción positiva que garanticen la igualdad real de oportunidades y de trato, y el pleno goce y ejercicio de los derechos reconocidos por esta Constitución y por los tratados internacionales vigentes sobre derechos humanos, en particular respecto de los niños, las mujeres, los ancianos y las personas con discapacidad). Se trata, en efecto, de un texto claro y terminante, a favor de la toma de medidas especiales a favor de las mujeres, particularmente en materia electoral.

Por lo dicho hasta aquí, en lo que debió ser el punto principal del fallo, esto es, la clarificación del significado constitucional del ideal de igualdad, la Cámara fracasa de modo rotundo, porque no alcanza a probar lo que declara probado (esto es, que este tipo de medidas positivas violan la igualdad). Lo que la Cámara debió hacer y no hizo, para justificar su rechazo a la "lista sólo de mujeres," es mostrar que una medida semejante implica un ejercicio irrazonable de la posibilidad constitucionalmente autorizada de tomar medidas positivas, en materia electoral, a favor de las mujeres. Como no hizo este ejercicio, ni probó su punto sobre la igualdad de otro modo, la decisión de la Cámara no es sostenible. Sin embargo, si hubiera hecho ese esfuerzo de razonamiento, hubiera encontrado dificultades para decir lo que quiso decir. Ello, porque lo que la Constitución intenta hacer con su toma de partido a favor de las acciones positivas para las mujeres en materia electoral, es confrontar un problema estructural, que sufren las mujeres y no los hombres, cual es el acceso a los cargos electivos. Del mismo modo, cuando la Constitución pide (en el art. 75 inc. 23) acciones positivas para "niños" y "ancianos" -medidas que podrían incluir, por ejemplo, la de asignarles subsidios económicos o apoyos sociales especiales- lo hace porque quiere hacerse cargo de un problema estructural, que el propio Estado, con el paso de los años, ha creado. En tal sentido, puede afirmarse sin un ápice de retórica, que la Constitución nacional se "desmarca" 
de un enfoque meramente formal de la igualdad, para abrazar otro mucho más cercano a lo que podríamos llamar "igualdad estructural": ello es lo que pretende asegurar exigiendo repetidamente la adopción de medidas especiales a favor de grupos especialmente vulnerables.

Por eso, si una política se dirigiera a crear un "ingreso básico para menores" (y no para ningún otro grupo), esa política se justificaría, aunque se privase del mismo beneficio a "todos los demás grupos," porque de lo que se trata es de combatir un problema estructural. Adviértase, sin embargo, que lo que dice la Cámara contra la peculiar acción positiva del caso (que ella "discrimina" a los demás, que los excluye, que viola la Constitución, que no toma a los demás como iguales, etc.) podría decirse contra el subsidio especial para menores. Otra vez: contra lo que dice la Cámara, se trata de medidas especiales que la Constitución autoriza y exige, para tratar de resolver o amenguar problemas estructurales, que sufren los grupos señalados (menores, mujeres, ancianos) y no otros.

Mientras el problema estructural se mantenga, y el compromiso constitucional con las acciones positivas para los sujetos afectados por ese problema estructural se mantenga (porque la Constitución no ha sido modificada), las listas electorales que no incluyan una proporción adecuada de mujeres representarán un problema constitucional, pero no así si no incluyen una proporción adecuada de hombres (o ninguno, como en este caso), porque ellos son ajenos al problema estructural que la Constitución enfrenta. Y dicha lista sólo de mujeres no será impugnable constitucionalmente, por otras cláusulas de la Constitución, del mismo modo en que no lo sería (ni podría considerarse "discriminatoria") una lista del Partido de los Jubilados que sólo incluyera a jubilados entre sus candidatos.

\section{Feminismo y democracia radical}

Una manera -no exitosa- que ensaya la Cámara para rechazar lo que la Constitución afirma -medidas positivas a favor de las mujeres en materia electoral, que pueden incluir una lista integrada sólo por mujeres- es la de señalar que se trata de un experimento extremo o radical. Para ello, la Cámara se refiere a, y descalifica de inmediato, a las alternativas del "feminismo radical" y la "democracia radical", con las que asocia a la medida del caso.

En su considerando 5, y citando al Tribunal Constitucional Español, la Cámara suscribe un párrafo sorprendente. La cita dice lo siguiente: 
"En el nuevo contexto normativo es ya innecesario compensar la mayor presencia masculina con candidaturas exclusivamente femeninas, por la sencilla razón de que aquel desequilibrio histórico deviene un imposible. Cierto que un ideario feminista radical que pretenda el predominio femenino no podrá ser constitucionalmente prohibido, pero tampoco podrá pretender sustraerse al mandato constitucional de la igualdad formal (art. 14 CE) ni a las normas dictadas por el legislador para hacer efectiva la igualdad material tal como establece el 9.2 CE" (cf. STC 52/08, del 29 de febrero). Por consiguiente, aclara que "no se impide la existencia de formaciones políticas que defiendan activamente la primacía de las personas de un determinado sexo, o que propugnen postulados que pudiéramos denominar «machistas» o «feministas». Lo que exige la disposición adicional que nos ocupa es que cuando se pretenda defender esas tesis accediendo a los cargos públicos electivos se haga partiendo de candidaturas en las que se integran personas de uno y otro sexo" (cf. STC 52/08 cit.).

La referencia al tribunal español confronta al menos dos graves problemas. En términos constitucionales, ella es totalmente inapropiada, porque la Constitución española carece de aquello que la Constitución Argentina afirma y subraya, esto es, un compromiso abierto con las acciones positivas a favor de las mujeres. Por ello, lo único que puede importar de aquella cita española la sugerencia según la cual una lista sólo de mujeres choca con el "mandato constitucional de la igualdad formal"- es justamente lo que no sirve para pensar el caso de la Argentina. Ello así, porque la Constitución de la Argentina aparece comprometida con una noción de igualdad diferente a la que prima en el texto español: en nuestra democracia constitucional prevalece una noción de igualdad estructural, que permite respaldar de modo enfático lo que la igualdad formal puede rechazar, eventualmente.

Por lo demás, la referencia al "feminismo radical" es equivocada, tanto en el Tribunal español como en la Cámara argentina, porque una lista electoral sólo integrada por mujeres (o jubilados o arquitectos) podría ser perfectamente defendida por posiciones feministas de todo tipo, incluyendo posiciones liberales, y también por posiciones no feministas, y aún libertarias (la "utopía" del libertario Robert Nozick está representada, justamente, por un mundo en donde distintos grupos se agrupan libremente, y del modo en que quieren, con el único límite de su libertad de conciencia y el consentimiento de los demás). Reducir la demanda por una noción fuerte de "igualdad real" al feminismo 
radical, representa un paso innecesariamente prejuiciado, de parte de los tribunales citados.

Si las escuetas referencias de la Cámara hacia el feminismo resultan desafortunadas, las que hace a la "democracia radical" resultan chocantes. Otra vez, la estrategia del tribunal argentino es la de apoyarse en las citas de un actor extranjero en busca del respaldo que no encuentra en la Constitución argentina. Todo el recorrido teórico de la Cámara, en torno a la noción de democracia, resulta entre sorprendente y preocupante: fundamentalmente, lo que nos ofrece son citas (en general anticuadas) de una diversidad de autores (Michels, Mosca, Pareto, Duverger, Hauriou, etc.), que resultan por completo innecesarias, ya que vienen a probar lo que nadie discute y lo que no está en juego: que la democracia representativa está en crisis, que los partidos políticos son importantes, etc. Luego de dicho recorrido, la Cámara afirma que, a partir de la reforma del 94, la Constitución argentina pasó de consagrar un sistema de democracia representativa a otro más participativo. Pero -aclara y subraya el tribunal- ello de ningún modo implicó la adopción de una democracia radical (una afirmación, según veremos, rechazable desde distintos ángulos).

La Cámara, a pesar de las citas que presenta, en ningún momento clarifica qué entiende por estas particulares concepciones de la democracia, y tampoco deja en claro cuál es el argumento para considerarlas ajenas a la Constitución, ni nos dice por qué habría que asociar una decisión tal como la de integrar a una lista sólo con mujeres o jubilados con una iniciativa "radical" o extrema. Otra vez, sin ningún argumento, la Cámara sostiene que la Constitución Nacional excluye a la "llamada democracia radical", que asocia -otra vez irrazonablemente y sin apoyo teórico- con "la pretensión de la democracia directa" y a la "denominada democracia inclusiva." La afirmación es extraña, y lo sería para cualquier tribunal del mundo: la democracia debe ser inclusiva! No puede tomarse dicha pretensión como una patología. En todo caso, la Cámara rechaza sin razones suficientes a la "democracia directa," por "resultar ilusoria y anárquica" (lo que obviamente es insostenible, tanto a la luz de regímenes de democracia directa, como el de Suiza, como a la luz de formas de democracia enfáticamente más directas, como la de Uruguay), y hace lo propio con la "democracia inclusiva," a través de la siguiente cita (particularmente infortunada). Ella dice:

"[l]a democracia inclusiva resulta mucho más preocupante desde el punto de vista democrático que $1[\mathrm{o}][\ldots]$ participativ[o] o [...] deliberativ[o]. Aquí se trata de reservar cuotas de representación a favor de grupos determinados por su 
condición, normalmente étnica, aunque podría ser de otro tipo: por niveles de renta, por discapacidad y un largo etcétera. [...]. En todo caso, las propuestas inclusivas recuperan posibles vetos a la aplicación de las leyes generales, a la manera de los tribunos de la plebe romanos. En definitiva, una pseudodemocracia que rompe la regla del demos integrado por ciudadanos libres e iguales. Por supuesto, los representantes de las minorías en proceso de inclusión deben actuar en la defensa de los intereses parciales y sectoriales del grupo al que representan. Así pues, democracia deliberativa e inclusiva son rigurosamente incompatibles, aunque muchos colegas simpatizan a la vez con una y con otra: o buscamos todos el interés general o cada uno representa a sus mandantes en busca de intereses particulares" (cf. Benigno Pendás García, "Democracia Constitucional o Democracia Radical ¿Es lícito vivir al margen de la política?". Separata de Anales de la Real Academia de Ciencias Morales y Políticas, Año LXVIII, Número 93, Curso académico 2015- 2016, Madrid, 2017).-

Nuevamente, la referencia a un académico español no hace sentido en el marco del fallo, simplemente porque la cita se apoya en un texto constitucional que difiere del nuestro en todo lo que en el caso en cuestión resulta relevante. Más todavía, el autor realiza unas consideraciones en materia de democracia que contradicen todo lo importante que se ha escrito sobre democracia, y en particular democracia deliberativa, en los últimos 50 años. En el contexto latinoamericano, por lo demás, que desde hace décadas ha constitucionalizado las cuotas a favor de minorías étnicas, resulta llamativa la descalificación de las "cuotas de representación a favor de grupos determinados por su condición, normalmente étnica," y su asociación con formas radicales de democracia: encontramos tales cuotas, por citar un caso, en el contexto colombiano, que dista enormemente de cualquier definición posible o imaginable de "democracia radical".

\section{Otros argumentos: teoría interpretativa y sentido común}

Aunque son muchas otras las consideraciones que hace la Cámara y que ameritarían un análisis por separado, en este último apartado voy a mencionar sólo uno, que se refiere al enfoque interpretativo que presenta el tribunal.

Todo lo que dice el fallo mayoritario en la materia resulta injustificado. Por un lado, y con cita a Bidart Campos, sostiene que "la interpretación debe hacerse integrando las normas en la unidad sistemática, comparándolas, 
coordinándolas y armonizándolas, de forma tal que haya congruencia y relación entre ellas". Como mostrara ya, la afirmación no se sostiene, ya que no hay un solo método interpretativo que los tribunales estén obligados a adoptar; ni es obvio que el enfoque interpretativo preferible sea el de la "armonización"; ni es cierto que la propia Cámara adopte y aplique este enfoque de modo mínimamente apropiado (por ejemplo, cuando se resiste a reconocer los vínculos que la Constitución del 94 establece entre las acciones afirmativas que consagra, la noción de igualdad real -que sólo aparece en este contexto- y el valor especial que le asigna a la mayor participación de las mujeres en política).

Más adelante, la Cámara vuelve sobre cuestiones de teoría interpretativa para señalar que una lista integrada sólo por mujeres sería contraria a "la intención del constituyente así como la de los congresistas tuvo como intención asegurar la igualdad de trato en el ámbito de lo político para varones y mujeres; pues, si bien es cierto la posición de desigualdad socio-cultural vigente en nuestro Estado, así como en muchas naciones del mundo, que tuvo como destinatario esencial la protección en particular de la mujer quien conformaba el colectivo desprotegido en el ámbito de esta actividad, jamás pudo estar en la télesis de las normas el consagrar una igualdad generando una desigualdad.- Por tanto, la inconsecuencia del legislador no se presume y jamás pudo estar en su espíritu que el destino de la norma ordenada a los fines de la protección de los derechos de la mujer pudiera conllevar la conculcación de los derechos de sus pares de género masculino."

Otra vez: cuál es el argumento que ofrece la Cámara para optar por un enfoque interpretativo "intencionalista" (tal vez de los enfoques interpretativos más implausibles con los que contamos, dada la imprecisión a la que -como puede verse en el caso- suele llevarnos)? Y cuál es la razón que nos propone el tribunal para que suscribamos tal particular lectura de lo que nuestros legisladores querían? Y de dónde deriva que ellos "jamás" pudieron "consagrar una igualdad generando una desigualdad"? Todo lo contrario: en situaciones de desigualdad estructural -que, como ocurre siempre, son producto de previas acciones y omisiones estatales- es habitualmente necesario operar alguna desigualdad de trato, destinada a remediar las desigualdades previamente creadas por el Estado. Nuevamente, lo único que importa en estos casos no es que se consagre una desigualdad, sino que no se consagre una desigualdad injustificada. Por lo demás, la decisión de crear deliberadamente desigualdades, está lejos de ser insólita o inaceptable o irracional. Sólo por citar un caso: todo lo escrito por John Rawls en su "Teoría de la Justicia" -tal vez el texto más 
influyente sobre la igualdad escrito en el último siglo- puede entenderse como un ejercicio destinado a mostrar cuáles desigualdades son justificadas en qué casos.

Finalmente, sorprenden también las consideraciones que hace la Cámara en respaldo del "sentido común," como base (adicional) para su fallo. Es curioso no sólo que el tribunal invoque como argumento el "modo de pensar o proceder tal como lo haría la generalidad de las personas" sino, sobre todo, que se asuma intérprete de ese sentido común, y que en adición considere que el sentido común respalda su decisión contraria a la lista de mujeres. En un fallo destinado a ver de qué modo se trata a minorías que sufren prejuicios extendidos, el último respaldo que podemos pretender o desear que adopte un tribunal, es el del supuesto sentido común mayoritario. 